\title{
The Equilibrium Dynamics for an Endogeneous Bid-Ask Spread in a Monopolistic Financial Market
}

\author{
J oão A maro de $M$ atos $^{1}$ and J oão Sobral do Rosário \\ Faculdade de Economia \\ Universidade Nova de Lisboa
}

February 2000

${ }^{1}$ Corresponding author: J oão Amaro de Matos. Address: Rua Marquês de Fronteira, 20, 1099-038 Lisbon, Portugal. email: amatos@fe.unl.pt 


\begin{abstract}
A bstract
This paper presents an endogeneous model for the stochastic dynamics of the bid-ask spread of prices of ..nancial assets. The model is derived introducing an intermediary and inventory costs in the setting of equilibrium ..nancial markets as described by Platen and R ebolledo (1996).
\end{abstract}

Keywords: Bid-ask spread; intermediary; dynamic equilibrium

J EL classi..cation: G10 


\section{Introduction}

An interesting microstructure question is how the design of a market axects the provision of immediacy, the bid-ask spread and the time series pattern of prices. An example of very recent interest in this issue is the paper by Hasbrouck (1999) implementing an empirical model for the discrete dynamics of the bid-ask quotes. Hasbrouck presents strong empirical evidence of stochastic behavior on the underlying microstructure factors that generate the time series patterns of prices. This, he argues, provides very good reasons to accommodate stochastic microstructure exects in statistical models of security price dynamics. Our note provides one such theoretical model for the dynamics of the bid and ask prices, which is based upon the simple setting for the equilibrium dynamics of ..nancial markets developed by Platen and Rebolledo (1996), extending it in order to incorporate a single, monopolistic, market-maker.

When considering the dynamics of the transaction process, the marketmaker is seen as an agent who provides a higher degree of liquidity, making it easier for transactions to occur at any point in time. This feature was introduced in a paper by Garman (1976) who suggested that the market-maker's policy is dependent on his inventories, in order to avoid market failure. This idea was developed by other authors such as A mihud and M endelson (1980), who related optimal inventory position to the behavior of the bid-ask spread and trading volume.

Illiquidity or related asymmetries of information justi..es the presence of a market-maker. This presence generates additional asymmetry by avoiding supply and demand sides to interact directly. The economic justi..cation of the intermediary is only complete if these asymmetries of information can be used to its own bene..t in order to construct a pro..t. In particular, Copeland and Galai (1983) and Glosten and Harris (1988) observe that the market-maker loses money from insider traders but compensates the losses with liquidity traders who are willing to pay a fee for immediacy. It is this balance that allows the existence of the market. For this reason, in the model to be developed below, the construction of the market-maker's pro..t will be centered on the needs of liquidity traders.

This note is organized as follows. Section 2 describes the model, ..rst presenting P laten and R ebolledo's equilibrium price process, then introducing an intermediary and changing the original equilibrium and, ..nally, stating the optimization problem and deriving the results. Section 3 concludes. 


\section{The M odel}

\subsection{The Starting Point}

In this paper we start by following the model proposed by Platen and $\mathrm{Re}$ bolledo (1996) to reach equilibrium price processes in security markets. In their model the demand has the following structure:

$$
D\left(t ; L_{t} ; 1 / \frac{d}{2}\right)=\text { at } ; \quad I L_{t}+p^{1 / \frac{d}{t}}:
$$

This demand has three components at every period in time: it is linearly (negatively) related to the security's price by the term $\mathrm{IL}_{\mathrm{t}}$; it has a price independent element at that accounts for the minimal amount of the security that will be traded; ..nally it has a third component $p^{1}$ te referred to as cumulative demand. In order to understand this last term, notice that $p$ is a constant and $1 / t_{t}$ is modeled in accordance with the stochastic dixerential equation

$$
d^{1} d_{\hat{z}}=n\left(\bar{L}_{t} ; \quad L_{t}\right) d t+b_{t} d W_{t}:
$$

In this equation $n$ is a simple positive constant, $\bar{L}_{t}$ is referred to as the security's agent risk neutral valuation, $W_{t}$ is a standard $W$ iener process (the model's noise source) and $b_{t}$ is a dixusion coet cient related to that noise source.

On the other hand, the supply has the following structure:

$$
S\left(t ; L_{t}\right)=a t+f L_{t}:
$$

Notice that in this model the supply originally has only terms corresponding to the ..rst two elements described in the demand. The third component is not considered by Platen and Rebolledo (1996) due to a more passive - they say - behavior from the supply side than from the demand side in the interaction leading to equilibrium. Solving the equilibrium condition $d S\left(t ; L_{t}\right)=d D\left(t ; L_{t} ;{ }^{1}{ }_{t}\right)$ for $L_{t}$ they arrive at the closed-form solution

$$
d L_{t}=\frac{n p}{f+1}\left(\bar{L}_{t} i L_{t}\right) d t+\frac{p b_{t}}{f+1} d W_{t}:
$$




\subsection{Introducing an Intermediary}

At this stage, a change in the structure of the above model is introduced. The economic agents on the supply side will not sell their goods directly to the economic agents on the demand side. A monopolistic market-maker is introduced in order to centralize information and trade and thus provide increased liquidity.

The earlier market of Platen and Rebolledo (1996) is segmented into two dixerent sub-markets: one where the former supply side faces the demand of the intermediary and the other where the former demand side faces the intermediary's supply. These are almost disjoint markets, in the sense that only the intermediary is a player common to both of them (although having dixerent roles).

Given the demand and supply functions in the former section, the intermediary has market power to choose the transacted amount $q_{t}$ establishing two dixerent equilibria, one in each sub-market. What links these two dixerent equilibria is that the transacted amount is the same in both sub-markets. Therefore, there will be two simultaneous, but not independent, price processes: the ask price, $L_{t}^{a}$, corresponding to the market where the intermediary plays the role of supply and the bid price, $\mathrm{L}_{\mathrm{t}}^{\mathrm{b}}$; corresponding to the market where the intermediary plays the role of demand.

A gain following Platen and R ebolledo (1996), one would write the demand function as

$$
D\left(t ; L_{t}^{a} ; 1 / \frac{d}{2}\right)=\text { at } i \quad I L_{t}^{a}+p^{1 / p}:
$$

Notice, however, that now this demand faces a supply of $q_{t}$, instead of the former supply function at $+f L_{t}^{a}$. On the other hand, the supply is rewritten as

$$
S\left(t ; L_{t}^{b} ; 1 / \frac{z}{z}\right)=a t+f L_{t}^{b}+S^{1 / \frac{z}{z}} ;
$$

facing, of course, a demand $q_{t}$ instead of the former demand function at $\mathrm{i} I \mathrm{~L}_{\mathrm{t}}^{\mathrm{b}}+\mathrm{p}^{1} \mathrm{z}$. Notice also that the supply has a new component, $\mathrm{s}^{1} / \overline{\mathrm{s}}$ referred to as cumulative supply and having a structure very similar to its counterpart in demand following the stochastic dixerential equation

$$
d^{1} / \tilde{t}=m\left(L_{t}^{b} i \quad L_{t}^{b}\right) d t+c_{t} d W_{t}:
$$


A ..nal element is added to our model. Although there is some controversy ${ }^{1}$ about the relevancy or not of the inventory costs for the optimal positioning of the market-maker, it is herein assumed, for the sake of completeness, that there is a cost function ' $\left(Q_{t}\right)$ for the inventory $Q_{t}$, suitably parametrized as a function of the transacted amount $q$ : The cost function is therefore given by $K\left(q_{t}\right)={ }^{B}+{ }^{-} q_{t}+{ }^{\circ} q_{t}^{2}$; where $K\left(q_{t}\right)$ is a positive, increasing function of $q_{t}$ with $\circledast_{;}^{-}, 0$ :

\subsection{The Statement of the Problem}

The problem is stated in the following way: $\max _{q} f q_{t}\left(L_{t}^{a} ; L_{t}^{b}\right) ; K\left(q_{t}\right) g$ subject to

$$
\begin{aligned}
& \text { at } i L_{t}^{a}+p^{1} / \frac{d}{t}=q t \\
& \text { at }+f L_{t}^{b}+s^{1 / s}=q t \\
& q t, 0
\end{aligned}
$$

The value function is the revenue minus the inventory cost for the intermediary at each point in time. The ..rst restriction relates the demand and the intermediary, giving rise to an ask price. The second restriction relates the supply and the intermediary. The resulting price is a bid price. In both cases the intermediary sets the same quantity $q_{t}$ to be traded, assumed to be positive. It follows that the equilibrium spread is positive. Solving each restriction to the price

$$
L_{t}^{a}=\frac{a t+p^{1 / \frac{d}{t}} i q_{t}}{1} \text { and } L_{t}^{b}=\frac{q_{t} i S^{1 / \frac{\beta}{z}} i \text { at }}{f} \text { : }
$$

Introducing $A=2\left(f+I+{ }^{\circ} f I\right)$; the solution of the maximization problem is then written as:

$$
\begin{aligned}
& q t=\frac{a t(f+I)}{A}+\frac{f p^{1} / \frac{1}{t}}{A}+\frac{\mid s^{1} / \frac{\beta}{z}}{A} i \frac{\left.f\right|^{-}}{A} \\
& L_{t}^{a}=\frac{\operatorname{at}(A ; f i I)}{I A}+\frac{p(A ; f)}{I A} 1 \frac{d}{A^{A}} i \frac{S}{A} 1 / \frac{f^{-}}{A}
\end{aligned}
$$

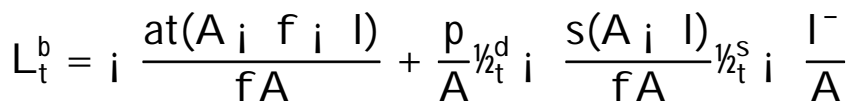

\footnotetext{
${ }^{1}$ See Hasbrouck and So..anos (1993) and references therein.
} 
Notice that the level of $q_{t} L_{t}^{a}$ and $L_{t}^{b}$ depend on ${ }^{-}$and ${ }^{\circ}$ : These variables follow dixusion processes and hence, the inventory cost $\mathrm{K}\left(q_{\mathrm{t}}\right)$ is also a dixusion. The prices follow the process

$$
\begin{aligned}
& d L_{t}^{a}=\frac{a(A ; f i I)}{I A} d t+\frac{p(A ; f)}{I A} d^{1} / \frac{f}{z} i \frac{s}{A} d^{1} / \tilde{z} ; \\
& d L_{t}^{b}=i \frac{a(A ; f i I)}{f A} d t+\frac{p}{A} d^{1} / \frac{A}{t} i \frac{s(A ; I)}{f A} d^{1} / \frac{\beta}{t}:
\end{aligned}
$$

Notice that the drifts and volatilities are stochastic but do not depend on - : In particular the spread $\mathrm{L}_{\mathrm{t}}^{\mathrm{a}} \mathrm{i} \mathrm{L}_{\mathrm{t}}^{\mathrm{b}}$ will have the stochastic drift

$$
\frac{a\left(A_{i} f i I\right)(f+I)}{2 f I A}+\frac{p\left(A_{i} f i I\right)}{I A} n^{i} \bar{L}_{t}^{a} i L_{t}^{a}{ }^{\Phi}+\frac{s\left(A_{i} f i I\right)}{f A} m^{3} L_{t}^{b} i L_{t}^{b}
$$

and a dixusion term $\frac{p\left(A_{i} f_{i} \mid\right)}{\mid A} b_{t}+\frac{s\left(A_{i} f_{i} \mid\right)}{f A} C_{t}$ :

\section{Conclusion}

Our model describes the dynamics of the bid and ask prices, and therefore, of the bid-ask spread. The approach was not to develop a model in which the behavior of the prices is determined endogenously by various factors ${ }^{2}$, but simply by the ..nancial market equilibrium conditions. From our results, we may derive several conclusions.

First, the expressions for the levels of the bid and ask prices and for the quantity traded show that these values depend on the parameters of the demand and supply curves and, as well, of the parameters of the cost function. Second, the drift and dixusion terms of the prices and of the spread depend on almost the same parameters. The only dixerence is that these terms do not depend on the linear term of the cost function. Therefore, if the cost structure is linear with respect to the traded amount, the evolution of the bidask spread will not depend on the inventory cost. Third, from the drift term

\footnotetext{
${ }^{2}$ Such as inventory costs and positions, informational exects, trade size, etc. See Easley and O'Hara (1987), Ho and Macris (1984), Glosten and Harris (1988) among others for discussion of the impact of these factors.
} 
of the spread, it is easily seen that a reversion of the spread to equilibrium values may occur or not depending on the values of the parameters.

The ultimate conclusion is that the estimation of these exects is of an empirical nature. Recent papers cited before use empirical models to describe such types of behavior, considering deterministic variation in the market parameters or even incorporating stochastic variation in volatility, and estimate the parameters in the economy. All these empirical issues can now be addressed in the context of this very simple equilibrium model for the dynamics of the spread.

\section{R eferences}

[1] A mihud, I. and H. M endelson, 1980, Dealership M arket. M arket-M aking with Inventory, J ournal of Financial E conomics, 8, 31-53.

[2] Copeland, T. and D. Galai, 1983, Information Exects on the Bid-Ask spread, The J ournal of F inance, 38, 1457-1469.

[3] Easley, D. and M. O'Hara, 1987, Price trade size and information in securities markets, J ournal of $F$ inancial Economics, 19, 69-90.

[4] Garman, M. B., 1976, Market Microstructure, J ournal of Financial Economics, 3, 257-275.

[5] Glosten, L. R. and L. E. Harris, 1988, Estimating the Components of the Bid-A sk Spread, J ournal of Financial E conomics, 21, 123-142.

[6] Hasbrouck, J., 1999, The Dynamics of Discrete Bid and Ask Quotes, J ournal of F inance, 54, 2109-2142.

[7] Hasbrouck, J. and G. So..anos, 1993, The trades of market makers: A n empirical examination of NY SE specialists, J ournal of Finance, 48, 15651593.

[8] Ho, T. and R. Macris, 1984, Dealer bid-ask quotes and transaction prices: An empirical study of some AMEX options, J ournal of F inance, 39, 23-45.

[9] Platen, E. and R. Rebolledo, 1996, Principles for Modelling Financial Markets, J ournal of A pplied Probability, 31, 601-613. 